\title{
CONSERVACIÓN IN VITRO DE CHAYOTE (Sechium edule)1
}

\author{
Silvana Alvarenga-Venutolo ${ }^{2}$, Ana Abdelnour-Esquivel ${ }^{2}$, Víctor Villalobos-Aránbula ${ }^{3}$
}

\begin{abstract}
RESUMEN
Conservación in vitro de chayote (Sechium edule). La técnica de conservación in vitro a mediano plazo fue examinada en chayote. Para ello se determinó la supervivencia de los brotes después de la adición de altas concentraciones de sacarosa $(0,30,50,60,70$ y $80 \mathrm{~g} / \mathrm{l})$ y ácido acetil salicílico $\left(10^{-9}\right.$, $10^{-6}$ y $\left.10^{-3} \mathrm{M}\right)$ al medio de cultivo, de disminuciones en la temperatura de crecimiento $\left(16,18,20,22\right.$ y $\left.25^{\circ} \mathrm{C}\right)$ y combinaciones de estos factores, en Costa Rica, en 1997. Se encontró que los brotes mantuvieron altos porcentajes de viabilidad después de ser conservados durante seis meses en los tratamientos evaluados. Debido a la apariencia más vigorosa y a la coloración más verde que presentaron las plántulas, se consideró que el mejor tratamiento fue la adición de $60 \mathrm{~g} / \mathrm{l}$ de sacarosa al medio de cultivo combinado con la incubación a $16^{\circ} \mathrm{C}$.
\end{abstract}

Palabras clave: Conservación, cultivo de tejidos, sacarosa, ácido acetil salicílico, temperatura.

\begin{abstract}
In vitro conservation of chayote (Sechium edule). The in vitro medium-term conservation technique was assayed on chayote. Survival was assayed after the addition of high concentration of sucrose $(0,30,50,60,70$ y $80 \mathrm{~g} / \mathrm{l})$ and acetyl salicylic acid $\left(10^{-9}, 10^{-6}\right.$ y $\left.10^{-3} \mathrm{M}\right)$ to the media culture and reduction on the temperature $\left(16,18,20,22\right.$ y $\left.25^{\circ} \mathrm{C}\right)$, in Costa Rica, 1997. It was found that shoots maintained high viability after a six month conservation period under the treatments evaluated. Based on vigor and coloration of plantlets, the best treatment seemed to be the addition of sucrose at $60 \mathrm{~g} / \mathrm{l}$ to the culture medium combined with incubation at $16^{\circ} \mathrm{C}$.
\end{abstract}

Key words: Conservation, tissue culture, sucrose, acetyl salicylic acid, temperature.

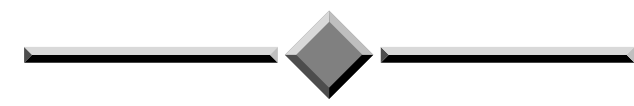

\section{INTRODUCCIÓN}

El chayote Sechium edule (Jacq.) Sw., (Cucurbitaceae), es originario de Mesoamérica, donde se encuentra la mayor diversidad genética, pero se cultiva de manera rústica en muchas regiones del mundo, siendo uno de los vegetales más accesibles para los grupos de bajos ingresos (Lira 1996).

Es una planta herbácea, monoica y trepadora, de frutos vivíparos y carnosos, utilizada principalmente como alimento humano. Los frutos, hojas tiernas y raíces tuberosas son consumidos como verdura, sin embargo, el consumo del fruto como vegetal de mesa es el más difundido. También se utilizan en la industria para la elaboración de alimentos infantiles, jugos, salsas y pastas, además se le atribuyen propiedades medicinales. Los tallos, duros y fibrosos, son la única parte de la planta que no se consume y se destinan a la fabricación artesanal de cestas y sombreros (Sosa 1997).

En la década de 1980 se incentivó la producción de chayote de exportación en Costa Rica y el área de

Recibido: 7 de junio, 2006. Aceptado: 6 de marzo, 2007.

2 Centro de Investigación en Biotecnología, Instituto Tecnológico de Costa Rica. Apartado postal 159-7050, Cartago, Costa Rica. Correo electrónico: salvarenga@itcr.ac.cr; aabdelnour@itcr.ac.cr

3 Centro de Investigación y de Estudios Avanzados del IPN (CINVESTAV), Irapuato, Mexico. Correo electrónico: vvilla@buzon.semarnap. gob.mx 
siembra ha mostrado una tendencia creciente desde entonces. Al exigir la demanda comercial una producción morfológicamente homogénea, los productores se han visto obligados a realizar una severa selección de fenotipos para satisfacer las demandas del mercado, pero esta práctica descarta la posibilidad de incorporar al mercado la notable variabilidad de frutos producida en los sistemas tradicionales de cultivo, lo que está resultando en una rápida erosión genética de la especie.

Para mantener la diversidad de la especie, así como de las poblaciones silvestres, y asegurar la disponibilidad de materiales de siembra para los agricultores y los programas de mejora genética, el establecimiento de bancos de germoplasma constituye una de las necesidades primordiales para chayote (Lira 1996). De ahí la importancia de desarrollar varias estrategias que permitan la conservación del germoplasma de chayote de una manera segura. Se afirma que el método más recomendable para una especie en particular dependerá de la forma de propagación que se utilice y del tipo de semilla que presente. Sin embargo, es importante señalar que el método seleccionado deberá garantizar altos porcentajes de viabilidad y la estabilidad genética de los materiales almacenados (Villalobos y Engelmann 1995).

En general, los bancos de semillas convencionales son adecuados para la preservación a largo plazo de especies ortodoxas, o sea, capaces de resistir un alto grado de desecación (alrededor del 6\% de humedad) y el almacenamiento a bajas temperaturas (entre $5^{\circ} \mathrm{C}$ y $-20^{\circ} \mathrm{C}$ ) sin perder viabilidad (Roberts 1973). Este tipo de almacenamiento es inapropiado o imposible para un gran número de especies cultivadas que poseen semillas recalcitrantes o son propagadas vegetativamente.

En chayote, la conservación de la semilla, bajo las condiciones descritas anteriormente, se hace imposible. El chayote se considera recalcitrante debido a que es vivíparo, es decir, la semilla no muestra período de latencia y germina en el fruto, se daña si se extrae y muere por desecación como resultado de la carencia total o parcial de testa lignificada (Newstron 1990; Flores 1989). Pruebas de almacenamiento de frutos de chayote han señalado que si éste se cosecha antes de brotar y se almacena en cámara fría a $5^{\circ} \mathrm{C}$ con baja humedad, la germinación puede retardarse únicamente seis semanas (Newstrom 1990). Para conservar estas especies problemáticas para el almacenamiento, las colecciones de campo y las colecciones in vitro son las opciones a considerar (Villalobos y Engelmann 1995).

Las colecciones de campo han sido el método tradicionalmente utilizado para la conservación de las especies recalcitrantes o propagadas vegetativamente y es el método que se ha utilizado tradicionalmente en chayote. Sin embargo, éstas son algo difícil de implementar ya que se deben considerar factores como el tamaño de la muestra requerido para conservar la diversidad y la heterocigocidad de la población y los requerimientos de terreno. Además, el alto riesgo de pérdida por factores climáticos, enfermedades y pestes, el mal manejo agronómico, los altos costos de mantenimiento y los cambios en las políticas institucionales o gubernamentales han demostrado que las colecciones de campo, como única opción de mantenimiento de germoplasma, de estas especies problemáticas a largo plazo, no es segura (Villalobos y Engelmann 1995). Esto parece confirmarse con chayote, ya que en Costa Rica se han realizado varias colectas de germoplasma de Mesoamérica, que resultaron en varias colecciones de campo en Turrialba (CATIE), Valle de Ujarrás (Cooperativa de Productores de Chayote) $y$, recientemente, en Heredia (Universidad Nacional), existiendo a la fecha, únicamente esta última colección (Abdelnour-Esquivel y Engelmann 2002).

Entre las opciones de conservación in vitro se mencionan las técnicas de conservación a largo plazo o crioconservación, que consiste en el almacenamiento del material vegetal a ultra baja temperatura $\left(-196^{\circ} \mathrm{C}\right)$, después de tratamientos que le permitan la sobrevivencia al congelamiento (Ashmore 1997). Esta modalidad fue evaluada en embriones cigóticos y ápices de chayote (Abdelnour-Esquivel y Engelmann 2002). También se recomiendan las técnicas de crecimiento reducido o conservación a mediano plazo, que consisten en el mantenimiento de los materiales (brotes, plántulas, meristemas) en condiciones físicas (factores ambientales) y químicas (composición del medio de cultivo) controladas, que permiten la reducción del crecimiento sin afectar la viabilidad y por ende, alargar al máximo los periodos de transferencia. Las más exitosas involucran la modificación del medio de 
cultivo y la reducción de la temperatura de crecimiento (Whiters 1991).

Por la problemática que presenta el germoplasma de chayote para su conservación, el objetivo de la presente investigación fue evaluar el efecto de la concentración de sacarosa, la temperatura, el ácido acetil salicílico (ASA) y la combinación de algunos de estos factores en la conservación in vitro a mediano plazo.

\section{MATERIALES Y MÉTODOS}

La presente investigación se llevó a cabo en la Unidad de Biotecnología del Centro Agronómico Tropical de Investigación y Enseñanza (CATIE), en 1997. Los frutos de chayote fueron colectados en la Zona de Ujarrás de Cartago, Costa Rica. Se utilizó la variedad conocida como quelite, que se caracteriza por tener una coloración verde claro, y un tamaño promedio de $15 \mathrm{~cm}$.

Las semillas fueron aisladas de frutos maduros y desinfectadas en una solución de hipoclorito de calcio al 4\% (p/v) con tres gotas de Tween-20 durante 10 minutos, y luego enjuagadas tres veces con agua destilada estéril en la cámara de transferencia de flujo laminar. En condiciones asépticas, los embriones fueron disectados, se les eliminaron las $2 / 3$ partes de los cotiledones y estos explantes fueron colocados en un medio M\&S (Murashige y Skoog 1962) enriquecido con $200 \mathrm{mg} / \mathrm{l}$ de caseína hidrolizada y $30 \mathrm{~g} / \mathrm{l}$ de sacarosa. $\mathrm{El} \mathrm{pH}$ fue ajustado a 5,7 antes del autoclavado $\left(121^{\circ} \mathrm{C}, 1,05 \mathrm{~kg} /\right.$ $\mathrm{cm}^{2}$, durante $20 \mathrm{~min}$ ) y como agente gelificante se agregó $1,5 \mathrm{~g} / \mathrm{l}$ de gelrite. Para la germinación de los embriones y el crecimiento de las plántulas, los cultivos fueron mantenidos en el cuarto de crecimiento con un fotoperiodo de 16 horas luz, 2.000 lux y $25^{\circ} \mathrm{C}$, excepto los experimentos en los que se varió la temperatura, en que los cultivos se mantuvieron en incubadores, y en las condiciones de fotoperiodo y luz anteriormente citadas (Alvarenga y Morera 1992).

Para los experimentos de conservación in vitro, las plántulas desarrolladas fueron seccionadas en los entrenudos, de manera que cada explante consistió de un segmento de $5 \mathrm{~mm}$ conteniendo un nudo y cultiva- das en viales de $40 \mathrm{ml}$ de capacidad con $10 \mathrm{ml}$ del medio de cultivo descrito anteriormente, suplementado con ácido nicotínico $(0,5 \mathrm{mg} / \mathrm{l})$, piridoxina $(0,5 \mathrm{mg} / \mathrm{l})$, tiamina $(0,1 \mathrm{mg} / \mathrm{l})$, myo-Inositol $(100 \mathrm{mg} / \mathrm{l})$ y sacarosa (30 g/l). Para las pruebas con diferentes concentraciones de sacarosa se emplearon $0,30,50,60,70$ y $80 \mathrm{~g} / 1$ adicionados al medio de cultivo para aquellas pruebas donde se evaluó el efecto del ácido acetil salicílico (ASA) se utilizaron concentraciones de $10^{-9}, 10^{-6}$ y $10^{-3}$ M. Se evaluaron diferentes temperaturas de incubación de los cultivos $\left(16,18,20,22\right.$ y $\left.25^{\circ} \mathrm{C}\right)$ como parte de la estrategia de conservación. Cada experimento consistió de 30 repeticiones por tratamiento.

Durante 30 días se condujeron experimentos para determinar las condiciones físicas (temperatura) y químicas (concentración de ASA y sacarosa) óptimas de cultivo, que produjeran inhibición del crecimiento sin afectar la sobrevivencia de los explantes. Las variables seleccionadas fueron: $16^{\circ} \mathrm{C}, 10^{-3} \mathrm{M}$ ASA y $6 \%$ de sacarosa. Una vez establecidos los tratamientos de conservación con la interacción de factores (temperatura-ASA: $16^{\circ} \mathrm{C}$ y $10^{-3} \mathrm{M}$, temperatura-sacarosa: $16^{\circ} \mathrm{C}$ y $6 \%$ de sacarosa), se realizaron ensayos a un plazo de seis meses. Las variables evaluadas durante la experimentación de conservación in vitro fueron: incremento promedio en longitud, peso fresco, peso seco, número de nudos por explante, supervivencia y morfología. Cada experimento consistió de 30 repeticiones por tratamiento.

El diseño experimental fue un irrestricto al azar, con arreglo factorial 2 x 2, para la determinación de la temperatura, concentración de ácido acetil salicílico y sacarosa que provocan la inhibición del crecimiento. Se realizaron los análisis de varianza respectivos y se efectuaron pruebas de Duncan para los diferentes tratamientos y sus interacciones.

\section{RESULTADOS}

\section{Efecto de la sacarosa}

Los experimentos conducidos durante 30 días para evaluar el efecto de diferentes concentraciones de sacarosa mostraron diferencias significativas de 
acuerdo a la prueba de rango múltiple de Duncan (Cuadro 1).

Cuadro 1. Efecto de la concentración de sacarosa en el crecimiento in vitro de brotes de chayote (Sechium edule) después de 30 días de cultivo. Turrialba, Costa Rica, 1997.

\begin{tabular}{ccccc}
\hline $\begin{array}{c}\text { Concen- } \\
\text { tración de } \\
\text { sacarosa } \\
\mathbf{g} / \mathbf{l}\end{array}$ & $\begin{array}{c}\text { Peso seco } \\
(\mathbf{m g}\end{array}$ & $\begin{array}{c}\text { Peso } \\
\text { fresco } \\
(\mathbf{m g})\end{array}$ & $\begin{array}{c}\text { Lon- } \\
\text { gitud } \\
(\mathbf{m m})\end{array}$ & $\begin{array}{c}\text { No. de } \\
\text { brotes }\end{array}$ \\
\hline 0 & $2,71 \mathrm{c}$ & $1,27 \mathrm{~b}$ & $0,51 \mathrm{c}$ & $0,78 \mathrm{a}$ \\
30 & $4,88 \mathrm{a}$ & $2,87 \mathrm{a}$ & $1,95 \mathrm{a}$ & $1,38 \mathrm{ab}$ \\
40 & $4,87 \mathrm{a}$ & $2,97 \mathrm{a}$ & $2,03 \mathrm{a}$ & $1,14 \mathrm{abc}$ \\
50 & $4,27 \mathrm{~b}$ & $2,75 \mathrm{a}$ & $1,75 \mathrm{ab}$ & $1,15 \mathrm{abc}$ \\
60 & $4,17 \mathrm{~b}$ & $2,72 \mathrm{a}$ & $1,38 \mathrm{bc}$ & $1,47 \mathrm{a}$ \\
70 & $3,81 \mathrm{~b}$ & $2,57 \mathrm{a}$ & $1,24 \mathrm{c}$ & $0,95 \mathrm{~cd}$ \\
80 & $3,77 \mathrm{~b}$ & $2,58 \mathrm{a}$ & $1,30 \mathrm{c}$ & $0,96 \mathrm{~cd}$ \\
\hline
\end{tabular}

Los datos fueron analizados utilizando ANOVA y la prueba de rango múltiple de Duncan. Datos seguidos de una misma letra no son estadísticamente diferentes.

Los brotes cultivados en ausencia de sacarosa, presentaron el menor incremento en crecimiento con base en el peso fresco, longitud y número de yemas producidas. Sin embargo, este tratamiento mostró el menor porcentaje de supervivencia (70\%). Para la variable de incremento en peso fresco, los tratamientos con $30 \mathrm{y}$ $40 \mathrm{~g} / \mathrm{l}$ de sacarosa mostraron los mayores incrementos, seguidos por los tratamientos con 60,70 y $80 \mathrm{~g} / \mathrm{l}$ de sacarosa. Respecto al efecto de la concentración de sacarosa sobre el peso seco, se observó una respuesta similar en todos los tratamientos que incluyeron la sacarosa en el medio de cultivo. Por otra parte, el análisis de los resultados para la variable incrementos en longitud, mostró cuatro grupos definidos: 30 y 40 g/l (los mayores incrementos), seguidos por 50 y 60 $\mathrm{g} / \mathrm{l}$. Los tratamientos que incluyeron 0,70 y $80 \mathrm{~g} / \mathrm{l} \mathrm{de}$ sacarosa mostraron los menores incrementos.

La mayor producción de yemas se observó con $60 \mathrm{~g} / \mathrm{l}$ de sacarosa, sin embargo; este tratamiento no se diferenció estadísticamente de los tratamientos que incluyeron 30, 40 y $50 \mathrm{~g} / 1$. Los tratamientos que mos- traron el menor número de yemas fueron los de 0,70 y $80 \mathrm{~g} / \mathrm{l}$ de sacarosa en el medio de cultivo. Es importante señalar que los tratamientos evaluados mostraron los siguientes porcentajes de sobreviviencia: más del 90\% después de los 30 días de cultivo en el control, el $82 \%$ de los tratamientos con altos niveles de sacarosa sobrevivieron, y en los tratamientos con ASA, el nivel de supervivencia fue de un $79,2 \%$.

Con base en los resultados obtenidos en este experimento, para observar el efecto de la inhibición del crecimiento, el porcentaje de supervivencia y el aspecto general de las plántulas, se seleccionó la concentración de $60 \mathrm{~g} / \mathrm{l}$ para los experimentos posteriores de conservación del germoplasma.

\section{Efecto del ácido acetil salicílico}

Para determinar la concentración de ácido acetil salicílico (ASA) que produjera reducción del crecimiento, pero que permitiera la obtención de altos porcentajes de supervivencia, se establecieron experimentos con brotes cultivados en el medio estándar para chayote, al que se le agregó la concentración de ASA a evaluar. El análisis de varianza mostró diferencias altamente significativas entre los tratamientos para las variables peso y longitud comparados con el tratamiento control (0 M ASA), observándose reducciones tanto en el peso fresco como en el seco, y en la longitud de los brotes después de 30 días, en cultivo con ASA. Por otra parte, para la producción de brotes no se observaron diferencias entre los tratamientos evaluados (Cuadro 2). Todos los tratamientos con ASA mostraron altos porcentajes de supervivencia (95\%). La concentración de $10^{-3} \mathrm{M}$ ASA fue seleccionada para experimentos posteriores, con base en los resultados obtenidos de inhibición del crecimiento.

Es importante resaltar que las plántulas cultivadas en el medio con ASA presentaron algunos cambios de coloración; este efecto fue muy marcado cuando se cultivaron en medios con altas concentraciones. En general, la decoloración fue más notoria en las partes más bajas de los explanes, y algunas veces en las hojas inferiores. De acuerdo con la evaluación microscópica de los materiales, el ASA no afectó la morfología de los materiales, pero indujo una mayor producción de tricomas. 
Cuadro 2. Efecto de la concentración de ácido acetil salicílico (ASA) en el crecimiento in vitro de brotes de chayote ( $S$. edule) después de 30 días de cultivo. Turrialba, Costa Rica, 1997.

\begin{tabular}{ccccc}
\hline $\begin{array}{c}\text { Concen- } \\
\text { tración de } \\
\text { ASA } \\
(\mathbf{M})\end{array}$ & $\begin{array}{c}\text { Peso } \\
\text { seco } \\
(\mathbf{m g})\end{array}$ & $\begin{array}{c}\text { Peso } \\
\text { fresco } \\
(\mathbf{m g})\end{array}$ & $\begin{array}{c}\text { Longitud } \\
(\mathbf{m m})\end{array}$ & $\begin{array}{c}\text { No. de } \\
\text { brotes }\end{array}$ \\
\hline 0 & $5,34 \mathrm{a}$ & $3,01 \mathrm{ab}$ & $2,28 \mathrm{a}$ & $1,64 \mathrm{a}$ \\
$10^{-9}$ & $4,74 \mathrm{bc}$ & $2,83 \mathrm{abc}$ & $1,69 \mathrm{bc}$ & $1,49 \mathrm{a}$ \\
$10-6$ & $4,95 \mathrm{~b}$ & $3,04 \mathrm{c}$ & $1,47 \mathrm{bc}$ & $1,44 \mathrm{a}$ \\
$10^{-3}$ & $4,58 \mathrm{bc}$ & $2,66 \mathrm{c}$ & $1,94 \mathrm{ab}$ & $1,56 \mathrm{a}$ \\
\hline
\end{tabular}

Los datos fueron analizados utilizando ANOVA y la prueba de rango múltiple de Duncan. Datos seguidos de una misma letra no son estadísticamente diferentes.

\section{Efecto de la temperatura}

Se obtuvo un $100 \%$ de sobrevivencia en todos los tratamientos. En estas pruebas se observaron diferencias significativas entre los explantes cultivados en el tratamiento control $\left(25^{\circ} \mathrm{C}\right)$ y los otros tratamientos evaluados (Cuadro 3). El tratamiento de incubación a $16^{\circ} \mathrm{C}$ produjo la mayor reducción del peso fresco, longitud y fue uno de los que indujeron la mayor reducción del peso seco y número de brotes. Además, las plantas cultivadas en este tratamiento fueron similares a las plántulas control, pero más pequeñas. Con base en estos resultados, la temperatura de $16^{\circ} \mathrm{C}$ fue seleccionada para los experimentos posteriores.

De acuerdo con los resultados obtenidos, todos los factores evaluados (concentración de sacarosa, ácido acetil salicílico y temperatura de incubación) mostraron un efecto positivo en la reducción del crecimiento de los brotes de chayote. Sin embargo, los menores incrementos en peso y longitud se observaron durante el cultivo de los brotes de chayote a temperaturas menores a la estándar $\left(25^{\circ} \mathrm{C}\right)$, seguido por el efecto causado por el estrés osmótico, producto de las altas concentraciones de sacarosa. Por otra parte, el menor impacto en el crecimiento de los brotes fue observado en aquellos tratamientos que incluyeron el ASA.
Cuadro 3. Efecto de la temperatura en el crecimiento in vitro de brotes de chayote (S. edule) después de 30 días de cultivo. Turrialba, Costa Rica, 1997.

\begin{tabular}{ccccc}
\hline & \multicolumn{4}{c}{ Promedio } \\
\cline { 2 - 5 } $\begin{array}{c}\text { Temperatu- } \\
\text { ra (C) }\end{array}$ & $\begin{array}{c}\text { Peso seco } \\
(\mathbf{m g})\end{array}$ & $\begin{array}{c}\text { Peso } \\
\text { fresco } \\
(\mathbf{m g})\end{array}$ & $\begin{array}{c}\text { Longitud } \\
(\mathbf{m m})\end{array}$ & $\begin{array}{c}\text { No. de } \\
\text { brotes }\end{array}$ \\
\hline 16 & $3,25 \mathrm{c}$ & $2,02 \mathrm{~b}$ & $1,28 \mathrm{bc}$ & $1,25 \mathrm{a}$ \\
18 & $3,54 \mathrm{~b}$ & $1,90 \mathrm{~b}$ & $0,84 \mathrm{c}$ & $0,89 \mathrm{~b}$ \\
20 & $3,99 \mathrm{~b}$ & $2,21 \mathrm{~b}$ & $1,36 \mathrm{bc}$ & $1,19 \mathrm{ab}$ \\
22 & $4,06 \mathrm{~b}$ & $1,17 \mathrm{bc}$ & $1,17 \mathrm{bc}$ & $1,05 \mathrm{ab}$ \\
25 & $4,76 \mathrm{a}$ & $2,78 \mathrm{a}$ & $2,05 \mathrm{a}$ & $1,36 \mathrm{a}$ \\
\hline
\end{tabular}

Los datos fueron analizados utilizando ANOVA y la prueba de rango múltiple de Duncan. Datos seguidos de una misma letra no son estadísticamente diferentes.

\section{Efecto de la interacción de los factores}

El efecto de la combinación de factores, sobre el crecimiento in vitro de brotes de chayote fue evaluado mediante el cultivo de los brotes en el medio de cultivo con $10^{-3} \mathrm{M}$ ASA, $60 \mathrm{~g} / \mathrm{l}$ de sacarosa a $16^{\circ} \mathrm{C}$ de temperatura, éstos mostraron una efectiva inhibición del crecimiento y mantuvieron la vigorosidad de los explantes, de acuerdo con los resultados obtenidos en los experimentos anteriores.

El crecimiento se evaluó después de un periodo de 30 días de cultivo. Cuando se compararon los resultados con el tratamiento control, se observó que la combinación de factores indujo cierta reducción del crecimiento, y en la mayoría de los casos, la disminución fue mayor que la producida por cada factor particular (Cuadro 4). Se encontraron diferencias estadísticamente significativas, entre el testigo y los tratamientos temperatura-ASA y temperatura-sacarosa en el promedio de incremento de peso seco y longitud. La interacción temperatura-ASA mostró el menor incremento en longitud, y la combinación temperatura-sacarosa mostró los menores incrementos en peso fresco y peso seco. Con respecto al número de yemas, no se obtuvieron diferencias significativas entre el 
Cuadro 4. Efecto de la interacción temperatura-ácido acetil salicílico y temperatura-sacarosa en el crecimiento in vitro de brotes de chayote (S. edule) después de 30 días de cultivo. Turrialba, Costa Rica, 1997.

\begin{tabular}{ccccc}
\hline Tratamiento & \multicolumn{4}{c}{ Promedio } \\
\cline { 2 - 5 } & $\begin{array}{c}\text { Peso seco } \\
(\mathbf{m g})\end{array}$ & $\begin{array}{c}\text { Peso fres- } \\
\text { co }(\mathbf{m g})\end{array}$ & $\begin{array}{c}\text { Lon- } \\
\text { gitud } \\
(\mathbf{m m})\end{array}$ & $\begin{array}{c}\text { No. de } \\
\text { brotes }\end{array}$ \\
\hline $\begin{array}{c}\text { Control } \\
30 \mathrm{~g} / 1 \text { sacaro- } \\
\text { sa, } 25^{\circ} \mathrm{C}\end{array}$ & $4,49 \mathrm{a}$ & $2,77 \mathrm{~b}$ & $1,95 \mathrm{a}$ & $0,93 \mathrm{a}$ \\
\hline $\begin{array}{c}\mathrm{T}-\mathrm{ASA} \\
16^{\circ} \mathrm{C} \text { y } 10^{-3} \mathrm{M} \\
\mathrm{ASA}\end{array}$ & $3,16 \mathrm{~b}$ & $2,11 \mathrm{~b}$ & $0,76 \mathrm{~b}$ & $0,97 \mathrm{a}$ \\
\hline $\begin{array}{c}\mathrm{T}-\mathrm{Sacarosa} \\
16^{\circ} \mathrm{C} \text { y } 60 \mathrm{~g} / 1 \\
\text { sacarosa }\end{array}$ & $2,70 \mathrm{~b}$ & $1,91 \mathrm{~b}$ & $0,88 \mathrm{~b}$ & $1,07 \mathrm{a}$ \\
\hline
\end{tabular}

Los datos fueron analizados utilizando ANOVA y la prueba de rango múltiple de Duncan. Datos seguidos de una misma letra no son estadísticamente diferentes.

tratamiento control y la combinación de factores, pero la combinación de $60 \mathrm{~g} / \mathrm{l}$ de sacarosa en el medio y una temperatura de $16^{\circ} \mathrm{C}$ tuvo un efecto de estimulación en la producción de yemas.

Los resultados obtenidos en los experimentos (Cuadro 4) se utilizaron como base para evaluar el efecto de la combinación de factores en la conservación de brotes de chayote por un periodo de tiempo mayor. Después de seis meses, los brotes cultivados en condiciones de $16^{\circ} \mathrm{C}$ y con $60 \mathrm{~g} / \mathrm{l}$ de sacarosa o $10^{-3}$ M ASA en el medio de cultivo mostraron resultados similares a los obtenidos en la prueba anterior. Para las variables evaluadas, la interacción de la temperatura con el ASA y con la sacarosa resultó en la inhibición del crecimiento (Cuadro 5). Sin embargo, se observaron diferencias estadísticamente significativas entre los tratamientos cuando se compararon con el control, pero no entre los tratamientos de combinación de factores; excepto para el número de yemas, el cual se incrementó en el tratamiento temperatura-sacarosa. A pesar de no diferir estadísticamente en las variables evaluadas, las plantas en el tratamiento temperaturasacarosa presentaron un aspecto más saludable y una
Cuadro 5. Efecto de la interacción temperatura-ácido acetilsalicílico y temperatura-sacarosa en el crecimiento in vitro de brotes de chayote ( $S$. edule) después de 60 días de cultivo. Turrialba, Costa Rica, 1997.

\begin{tabular}{ccccc}
\hline Tratamiento & \multicolumn{4}{c}{ Promedio } \\
\cline { 2 - 5 } & $\begin{array}{c}\text { Peso seco } \\
(\mathbf{m g})\end{array}$ & $\begin{array}{c}\text { Peso fres- } \\
\text { co }(\mathbf{m g})\end{array}$ & $\begin{array}{c}\text { Longitud } \\
(\mathbf{m m})\end{array}$ & $\begin{array}{c}\text { No. de } \\
\text { brotes }\end{array}$ \\
\hline $\begin{array}{c}\text { Control } \\
30 \mathrm{~g} / \mathrm{L} \mathrm{sacaro-} \\
\mathrm{sa}, 25^{\circ} \mathrm{C}\end{array}$ & $5,78 \mathrm{a}$ & $2,49 \mathrm{a}$ & $2,49 \mathrm{a}$ & $1,10 \mathrm{~b}$ \\
\hline $\begin{array}{c}\mathrm{T}-\mathrm{ASA} \\
16^{\circ} \mathrm{C} \mathrm{y} 10^{-3} \mathrm{M} \\
\mathrm{ASA}\end{array}$ & $4,08 \mathrm{~b}$ & $1,69 \mathrm{~b}$ & $1,69 \mathrm{~b}$ & $1,08 \mathrm{~b}$ \\
\hline $\begin{array}{c}\mathrm{T}-\mathrm{Sacarosa} \\
16^{\circ} \mathrm{C} \text { y } 60 \mathrm{~g} / \mathrm{l} \\
\text { sacarosa }\end{array}$ & $4,04 \mathrm{~b}$ & $1,74 \mathrm{~b}$ & $1,74 \mathrm{~b}$ & $1,43 \mathrm{a}$ \\
\hline
\end{tabular}

Los datos fueron analizados utilizando ANOVA y la prueba de rango múltiple de Duncan. Datos seguidos de una misma letra no son estadísticamente diferentes.

coloración más verde que las plántulas control, o en el tratamiento temperatura-ASA.

\section{DISCUSIÓN}

Son muchas las ventajas que se atribuyen a la conservación in vitro a mediano plazo; entre las más destacadas están: las colecciones que se mantienen bajo condiciones estériles en un ambiente controlado (libres de enfermedades y de fluctuaciones climáticas), además, las plantas pueden ser rápidamente propagadas cuando se van a utilizar. Por otra parte, el espacio y las labores requeridas para el mantenimiento de la colección, se reducen considerablemente con respecto al mantenimiento de las colecciones de campo. Las mayores desventajas de esta modalidad de conservación, es que requieren infraestructura y equipo especializado, por otra parte, se debe contar con una fuente segura de electricidad.

Bajo la modalidad de conservación in vitro a mediano plazo están siendo conservadas las colecciones mundiales de yuca (CIAT, Colombia), papa 
(CIP, Perú), Musa spp. (INIBAP, Centro de tránsito, Bélgica), ñame (IITA, Nigeria), pera, mora y varios frutales de clima templado (National Clonal Germplasm Repository, Oregon, Estados Unidos) y otros (Ashmore 1997).

Las técnicas de cultivo de tejidos son útiles para la conservación del germoplasma vegetal, especialmente para especies recalcitrantes, como el chayote, que no resisten el almacenamiento en las condiciones utilizadas en los bancos de semillas convencionales. La conservación en condiciones in vitro se utiliza para respaldar las colecciones de campo y asegurar la existencia del recurso. Generalmente, la reducción del crecimiento en condiciones in vitro se puede lograr disminuyendo en unos grados centígrados la temperatura del cuarto de crecimiento, y reduciendo la intensidad o las horas luz, dependiendo de la sensibilidad de la especie. También puede lograrse modificando la concentración de nutrientes en el medio de cultivo, eliminando o disminuyendo la concentración de los reguladores de crecimiento o adicionando algún retardador del crecimiento. En otros casos, el uso de osmoreguladores como la sacarosa, han sido favorables para retardar el desarrollo (Engelmann 1991; Ashmore 1997).

En la presente investigación, la reducción del crecimiento y la inducción de brotes en los explantes de chayote, cultivados en concentraciones de sacarosa mayores de $30 \mathrm{~g} / 1$ pudo ser el resultado del estrés osmótico al que se sometieron, además de la interacción de la sacarosa con niveles endógenos de auxinas, respectivamente (Bathia 2005). De acuerdo con Sakuta et al. (1987), el tamaño y el número de células se reducen tanto por incrementos en la concentración de sacarosa, como por el potencial hídrico del medio. Por otra parte, Thorpe (1985) señala que la concentración de sacarosa puede inducir efectos dramáticos en el crecimiento y morfogénesis de las plantas.

Los tratamientos con ASA indujeron la reducción en el peso seco y longitud de los brotes. Sin embargo, la producción de nuevos brotes o yemas no se vio afectada. Estos resultados coinciden con los encontrados en el cultivo in vitro de Cucumis melo con el empleo del ASA en concentraciones de 50 a $200 \mu \mathrm{M}$, en esta especie se produjo la estimulación de la producción de Bencil Adenina, lo que estimuló la organogénesis en tallos de esta especie (Shetty et al. 1992)

El ácido acetil salicílico se encuentra en muchas plantas como un compuesto natural, y muestra una amplia variedad de efectos en los diferentes procesos biológicos como: organogénesis in vitro de brotes, inhibición de la producción de etileno (Popova et al. 1997); estimulación de la embriogénesis somática en Pelargonium (Hutchinson y Saxena 1996), inducción floral en Lemna (Ben-Tal y Cleland 1982; Kahiara et al. 1981; Oota 1975), resistencia contra infecciones virales (Dennis y Guest 1995), fungosas (Walters et al. 1993) y bacteriales (Dennis y Gust 1995; Saint-Pierre et al. 1984; Popova et al. 1997). También se ha mostrado su efecto en el mecanismo de cierre estomático y en la reducción de la transpiración (Larqué-Saavedra 1978).

El efecto del ASA en la inhibición del crecimiento ha sido informado en especies como Triticum (Larqué-Saavedra 1975) y Solanum cardiophyllum (Lopez 1987); de acuerdo con los resultados obtenidos en este estudio, el chayote podría incluirse en este grupo. Tanto la inhibición del crecimiento como la estimulación en la producción de yemas se han explicado a través de la evidencia mostrada en estadios tempranos del crecimiento del explante.

El ASA inhibe la producción de etileno y reduce la concentración interna de auxina, favoreciendo la acumulación de citocininas y la producción de yemas (Lieberman 1979; Shetty et al. 1992). Al parecer el ASA actúa sobre la enzima productora de etileno, responsable de catalizar la conversión de 1- Aminociclopropano ácido carboxílico (ACC) a etileno, por inhibición no competitiva (Lesli y Romani 1988).

También se menciona que altas concentraciones de ASA pueden producir una disminución en el contenido de clorofila, y afectar la regulación de algunas reacciones durante la fotosíntesis (Popova et al. 1997), lo que ayudaría a explicar la apariencia clorótica de las plántulas de chayote en los tratamientos con este compuesto.

En general, la temperatura controla el crecimiento y desarrollo debido a su efecto en la actividad metabólica, 
específicamente en la actividad enzimática. Este factor físico puede alterar muchos eventos morfológicos (Parkin y Jung-Kuo 1989; Duncan y Wildholm 1987). Las bajas temperaturas inducen la producción de ácidos grasos insaturados y prolina, que a la vez confieren resistencia al estrés (Withers 1985; Duncan y Wilholm 1987). Las bajas temperaturas para la conservación in vitro de germoplasma vegetal se han utilizado en una amplia variedad de especies de clima templado y tropical, sin embargo; las especies tropicales son muy sensibles a temperaturas menores de $15^{\circ} \mathrm{C}$, sufriendo daños irreversibles (Roca 1985; Ashmore 1997). De esto se deriva la importancia de realizar estudios que permitan determinar la temperatura mínima de almacenamiento que sea capaz de reducir el crecimiento y a la vez, aumentar la tasa de supervivencia después de largos periodos de conservación.

Aún cuando en este estudio el tratamiento que consistió de la adición de sacarosa a $60 \mathrm{~g} / \mathrm{l}$ al medio de cultivo, combinada con la incubación a $16^{\circ} \mathrm{C}$ no difirió estadísticamente del tratamiento de combinación temperatura-ASA, después del periodo de conservación, estas plántulas mostraron una apariencia más saludable y una coloración más verde, lo que pareciera indicar que el periodo de conservación para las plántulas en este tratamiento podría extenderse. Por lo anterior, el tratamiento que combina una temperatura de $16{ }^{\circ} \mathrm{C}$ con $60 \mathrm{~g} / \mathrm{l}$ de sacarosa en el medio de cultivo se sugiere para la conservación a mediano plazo de brotes de chayote.

\section{LITERATURA CITADA}

ALVARENGA, S.; MORERA, J. 1992. Micropropagación in vitro del chayote (Sechium edule Jacq. Sw). Tecnología en marcha 11(3):31-42.

ABDELNOUR-ESQUIVEL, A.; ENGELMANN, F. 2002 Cryopreservation of chayote (Sechium edule JACQ. SW.) zygotic embryos and shoot-tips from in vitro plantlets. CryoLetters 23:299-308.

ASHMORE, S.E. 1997. Status report on the development and application of in vitro techniques for the conservation and use of plant genetic resources. International Plant genetic Resources Institute, Roma, Italia. 67 p.
BATHIA, P. 2005. Effect of nutrient media and sucrose concentration on shoot organogenesis in tomato. J. Plant Biotechnology 7(1):57-65.

BEN-TAL, Y.; C.P. CLELAND. 1982. Influence of giving salicylic acid for different time periods on flowering and growth in the long-day plant Lemna gibba $\mathrm{G}_{3}$. Plant Physiology. 70: 287-290.

DENNIS, J. C.; GUEST, D. I. 1995. Acetiyl salicylic acid and beta-ionone decrease the susceptibility of tabacco to tabacco necrososis virus and Phytophtora parasitica var. nicotianae. Australasian Plant Pathology. 24:57-64.

DUNCAN, D. R.; WIDHOLM, J. M. 1987. Prolin accumulation and its implication in cold tolerance of regenerable maize callus. Plant Physiology. 83(3):703-708.

ENGELMANN, F. 1991. Tropical plant germplasm conservation. In: Conference of the International Plant Biotechnology Network. (4, 1991, San José, Costa Rica) Proceedings of Biotechnology for Tropical Crop Improvement In Latin America. p. 51-73.

FLORES, E. 1999. La planta, estructura y función. Volumen II. LUR (Libro Universitario Regional). Editorial Tecnológica de Costa Rica. Costa Rica. p. 698.

HUTCHINSON, M.J.; SAXENA, P.K. 1996. Acetyl salicylic acid enhances and synchronizes thidiazuron induced somatic embryogenesis in geranium (Pelargonium X hortorum Bailey) tissue cultures. Plant Cell Reports. 15:512-515.

KIAHARA, S.; WATANABE, K.; TAKIMOTO, A. 1981. Flower inducing effect of benzoic and salicylic acids in various strains of Lemna pancicostata and L. minor. Plant \& Cell Physiology 22(5):819-821.

LARQUÉ-SAAVEDRA, A. 1978. The antitranspirant effect of acetyl salicylic acid on Phaseolus vulgaris. Physiol. Plant. 43:126-128.

LARQUÉ-SAAVEDRA, A. 1975. Studies on hormonal aspects of plant growth in relation to chemical environmental treatments. $\mathrm{Ph}$. D. Thesis. London University. London, England.

AGRONOMÍA MESOAMERICANA 18(1): 65-73. 2007 
LESLIE, C.; ROMANI, R.J. 1988. Inhibition of ethylene biosynthesis by salicylic acid. Plant Physiology. 88:833-837.

LIEBERMAN, M. 1979. Biosynthesis and action of ethylene. Annual Review of Plant Physiology . 30:533-591.

LIRA, R. 1996. Promoting the conservation and use of underutilized and neglected crops. Chayote (Sechium edule Jacq.) SW. Roma, Italia. IPGRI. 58p.

LIRA-SAADE, R. 1995. Estudios taxonómicos y ecogeográficos de las cucurbitáceas de latinoamericanas de importancia económica. Systematic and ecogeographic studies on crop genepools. 9. Rome, Italy. Internacional Plant Genetic Resources Institute. p. 116-161.

LÓPEZ, H. 1987. Efecto del ácido acetil salicílico en el crecimiento de yemas de Solanum cardiophyllum (Lindl.) cultivados in vitro. Tesis Mag. Sc. Colegio de Postgraduados. Chapingo, Mexico. 86p.

MURASHIGE, T.; SKOOG, F. 1962. A revised medium for rapid growth and bioassays with tobacco tissue cultures. Physiol. Plant. 15:473-497.

NEWSTROM, 1990. Origen and evolution of chayote. In: Bates, Robinson and Charles eds. Biology and utilization of the Cucurbitaceae. Cornell University Press. p. 141-149.

OOTA, Y. 1975. Short-day flowering of Lemna gibba $\mathrm{G}_{3}$ induced by salicylic acid. Plant \& Cell Physiology. 16:1131-1135.

PARKIN, K. L.; JUNG-KUO, S. 1989. Chilling-induced lipid degradation in cucumber (Cucumis sativa L. cv Hybrid C) fruit. Plant Physiology 90:1049-1056.

POPOVA,L.; PANCHEVA, T.; UZUNOVA,A. 1997. Salicylic acid: Properties, biosynthesis and physiological role. Bulg. J. Plant Physiol. 23:85-91.

ROBERTS, E.H. 1973. Predicting the viability of seeds. Seed Sci. Technol. 1:499-514.
ROCA, W. 1985. El cultivo de tejidos para la conservación de los recursos genéticos in vitro. Consejo Internacional de Recursos Fitogenéticos (CIRF). Lecturas sobre Recursos Fitogenéticos 3. Cali, Colombia. 39p.

SAINT-PIERRE, B; MIVILLE, L.; DION, P. 1984. The effects of salicylatics on phenomena's related to crown gall. Canadian Journal of Botany. 62:729-734.

SAKUTA, M.; TAKAGI, T.; KOMAMINE, A. 1987. Effects of sucrose on betacyanin accumulation and growth in suspension cultures of Phytolacca americana. Physiol. Plant. 71:455-458.

SHETTY, K.; SHETTY, G.A.; NAKAZAKI, Y.; YOSHIOKA, K; ASANO, Y.; OOSAWA, K. 1992. Stimulation of benzyladenine-induced in vitro shoot organogenesis in Cucumis melo L. by proline, salicylic acid and aspirin. Plant Science Limerick. 84:193-199.

SOSA, R. 1997. El poder medicinal de las plantas. Miami, Florida, Estados Unidos de América. Asociación Publicadora Interamericana. p. 223.

THORPE, T. A. 1985. Carbohydrate utilization and metabolism. In: Bonga, J.M.; Durzan, D.J. eds. Tissue Culture in Forestry. 2 ed. Dordrecht. Martinus Nijhoff/Dr. w-Junk. p. 325-368.

VILLALOBOS, V. M.; ENGELMANN, F. 1995. Ex situ conservation of plant germplasm using biotechnology. World Journal of Microbiology \& Biotechnology 11: 375-382.

WALTERS, D.R.; MITCHELL, A.F.; HAMPSON, J.; MCPHERSON, A. 1993. The induction of systemic resistance in barley to powdery mildew infection using salicylates and various phenolic acids. Annals of Applied Biology 122:451-456.

WHITERS, L. 1991. Maintenance of plant tissue cultures. In: Maintenance of microorganisms. 2 ed. Academic Press. London. p. 243-285. 